\title{
Restauración digital de la fotografía: un concepto erróneo
}

\author{
Dr. Miguel B. Márquez \\ Miembro del Grupo de Investigación en Estructura, Historia y Contenidos de la Comunicación \\ Secretario de la Sociedad de Historia de la Fotografía Española \\ correo-e: miguelbmarquez@yahoo.es
}

\section{RESUMEN}

El autor, que lleva 30 años en el mundo de la fotografía, dedicado tanto a las actividades de investigación en este medio, como a la práctica del mismo y a la docencia, reflexiona en este artículo acerca de un concepto que ha aparecido últimamente, el de la denominada restauración digital. Para ello, en un primer paso, se basa en las acepciones de los términos que figuran en los diccionarios.

Seguidamente da un repaso a los conceptos de restauración, que se remontan al siglo $X I X, y$ concluye trazando un breve bosquejo sobre los planteamientos internacionales en la actualidad.

Finalmente, demuestra que el concepto de restauración digital, tal y como está planteado, es erróneo y propone la utilización del concepto recreación digital, que no entra en contradicción con los postulados de la Carta del Restauro y ni con los existentes en otros medios de expresión, con más tradición en este campo.

\section{ABSTRACT}

The author, who has been thirty years in the world of the photography, dedicated so much to the investigation activities in this means, like a the practice of the same one and to teaching, reflects in this article about a concept that has appeared lately, the one of the denominated digital restoration. For it, on a first step, one is based on the meanings of the terms that appear in the dictionaries.

Next he gives a review to the restoration concepts, that go back to century XIX, and concludes drawing up a brief sketch on the international expositions at the present time.

Finally, he demonstrates that the concept of digital restoration, so and as is raised, is erroneous and proposes the use of the concept digital recreation, that does not enter contradiction with the postulates of the Letter of Restauro and nor with the existing ones other means of expression, with the more tradition in this field.

Palabras claves: Restauración/Conservación/Reconstrucción/Recreación/Restauro/Fotografía/ Digital.

Key words: Restoration/Conservation/Reconstruction/Recreation/Restauro/Photography/Digital. 
Hace algunos años, pocos todavía, que se viene detectando el uso de una terminología nueva en los textos aparecidos en el mercado español sobre restauración y/o conservación fotográfica. Incluso ya se vislumbra la aparición de algún texto que debate acerca de la restauración virtual. Ello nos ha impulsado a plantear una reflexión sobre lo que se denomina digital así como lo concerniente al término restauración. Una reflexión que efectuaremos de manera breve pero concisa. Quede bien claro que nuestra única intención es aportar una vía de aclaración a una terminología que puede resultar confusa o, cuando menos, equívoca para quienes se aproximan al mundo de la conservación y restauración de los materiales objeto de nuestro estudio.

\section{Lo digital}

Las acepciones halladas en los diccionarios aún no han incorporado el concepto digital tal y como suele ser utilizado en la prensa periódica y los manuales españoles. Los franceses, más dados que nosotros a la preservación de su idioma, han traducido cuantos términos informáticos han podido. Así, al software lo denominan le logiciel; al hub, concentrateur; al password, mot de passe y a lo digital le numérique, por poner sólo unos ejemplos elegidos al azar.

En efecto, según aparece en la $2^{\mathrm{a}}$ acepción del DRAE, digital es lo referente a los números dígitos y en particular a los instrumentos de medida que la expresan con números dígitos ${ }^{1}$. Por su parte, el Diccionario de uso del español define el término como susceptible de ser expresado en cifras, o sea, contable ${ }^{2}$. Poco aporta a nuestras investigaciones la utilización de estas herramientas. Únicamente que el término está relacionado con los números. Sin embargo, el Manual de español urgente de la Agencia EFE, acepta el vocablo digitalizar como transformación de una información en una sucesión de números para su tratamiento informático ${ }^{3}$.

Podemos, pues, determinar que lo digital es lo concerniente a toda acción relativa a la transformación de una información en caracteres numéricos para facilitar el tratamiento informático de la misma.

\section{Sobre el concepto de restauración}

La búsqueda del término en el DRAE aparece como acción de restaurar. Es decir, reparar, renovar o volver a poner una cosa en aquel estado o estimación que antes tenía $a^{4}$, en la $2^{\mathrm{a}}$ acepción. Igual que en el término anterior, poco nos aporta, aunque alude a una acción que se efectúa sobre un objeto y sólo sobre él.

\footnotetext{
1 Real Academia Española. Diccionario de la lengua española (versión 2.0). Espasa Calpe, Madrid, 1998. 2 Id

3 Agencia EFE. Manual de español urgente. Cátedra, Madrid, 2001 (17 a edic.).

4 Real Academia Española. Diccionario de la lengua española (versión 2.0). Espasa Calpe, Madrid, 1998.
} 
El Diccionario de uso del español, también en su segunda acepción, define restaurar como arreglar una cosa estropeada o rota, particularmente un edificio o una pieza de arte, dándole aspecto de nueva ${ }^{5}$. Como puede verse, coincide en lo fundamental con la correspondiente al DRAE al referirse a una acción efectuada sobre un único objeto ya existente.

\section{Restauración digital}

De lo anteriormente expuesto puede inferirse que el concepto de restauración digital atiende a las tareas de arreglo de una información transformada en una sucesión de números para su tratamiento informático y que, por alguna circunstancia, ha podido deteriorarse. Esta es una circunstancia que se produce muy a menudo en el mundo de la informática cuando un archivo sufre algún daño, bien por una avería en las cabezas lectoras o grabadoras, en el envío del mismo a través de Internet, o por cualquier otra razón.

Pero, investigando en la escasa literatura sobre el tema existente hasta el momento, hemos encontrado un texto que reproducimos seguidamente:

La restauración óptica representa una alternativa a los procesos tradicionales de restauración encaminados a la mejora del aspecto visual de la imagen. En lugar de intentar recuperar los soportes se orienta a la recuperación del contenido icónico de fotografías cuya imagen se ha deteriorado. Para ello utiliza técnicas especiales de copiado (iluminación, filtros, película y revelado). La restauración digital está guiada por los mismos criterios que la anterior pero en lugar de los métodos de copiado y duplicado tradicionales utiliza las posibilidades que brinda la tecnología informática de tratamiento de imágenes digitales ${ }^{6}$.

Ello supone, según estos autores, que la restauración no se efectúa sobre el objeto en sí, sino sobre otro objeto diferente por lo que, de acuerdo con la definición extraída del DRAE, no se trata de una restauración: estamos hablando de otra cosa.

El texto que acabamos de leer tiene también su correspondencia en el mundo de la pintura y la arquitectura. Imaginemos que se trata de restaurar un cuadro y, en lugar de actuar sobre el lienzo, lo hacemos sobre una reproducción digital del mismo. Ítem más, supongamos que tratamos de restaurar el Coliseo romano, y las tareas pertinentes las hacemos sobre una visualización digital de carácter tridimensional del monumento. En estos casos ¿estaremos hablando verdaderamente de restauración? ¿O, tal vez, reservamos la denominación de restau-

5 Moliner, María. Diccionario de uso del español (versión 1.1). Gredos, Madrid, 1997.

6 Fuentes de Cía, Ángel María; Robledano Arillo, Jesús. "La identificación y preservación de los materiales fotográficos", en Del Valle Gastaminza, Félix (Edit.). Manual de documentación fotográfica. Síntesis, Madrid, 1999. Pág. 70. 
ración digital exclusivamente al mundo de la fotografía? Porque, si verdaderamente se citan esos casos como restauración, el espectador puede quedar defraudado si, al ir a visitar esas obras, las contempla de manera distinta a como se le ha enseñado después del tratamiento de las mismas mediante el ordenador.

Para resolver estas cuestiones indaguemos lo que nos dicen sobre el tema los estudiosos de la restauración, de tanta tradición en Europa, así como los acuerdos adoptados por los países de nuestro entorno, recogidos en una amplia normativa de carácter internacional bajo los auspicios de instituciones como Universidades de todo el mundo, Icomos, Icrom, Unión Europea, UNESCO, etc.

\section{Las cartas del Restauro}

La preocupación por la restauración de monumentos se remonta a la antigüedad, si bien en su concepción más moderna, la que ha dado un mayor empuje a la investigación en este terreno, tiene su punto de partida en la transición del siglo XVIII al XIX.

A lo largo del XIX fueron tres las corrientes que se manifestaron, especialmente en el mundo de la arquitectura:

1. La neoclásica, que se basa en el principio de la reconstrucción del monumento valiéndose de las partes originales o de la reproducción de las mismas.

2. La restauración romántica, encabezada por Viollet-le-Duc y John Ruskin quienes defendían, respectivamente, la reconstrucción total de los monumentos mediante la analogía, y la intocabilidad de los mismos.

3. La restauración positivista, cuyos máximos representantes fueron Camillo Boito y Luca Beltrami. Estos defendían postulados de salvaguarda del monumento (Boito) y la recreación (Beltrami).

Sobre la base de estos planteamientos, a lo largo del siglo XX se manifiesta la intención de instaurar unas normas de carácter internacional, tendentes a establecer unos principios que posibiliten tanto la salvaguarda como la posterior utilización de los edificios objeto de restauración, sin que ello suponga una alteración de las características de los mismos. Nace así la primera Carta del Atenas de 1931. Desde entonces han sido muchas las reuniones de expertos en temas de restauración, conservación, arquitectura, etc., que se han venido celebrando por todo el mundo, hasta el punto de desarrollarse Cartas de carácter regional tendentes a conservar el patrimonio de determinadas zonas del planeta con características específicas.

Desde la Carta de Atenas (1931), han aparecido la de Venecia (1964), Florencia (1981) dedicada a los jardines históricos, y la de Toledo (1986) para la conservación de las ciudades históricas. Todas ellas son Cartas de carácter internacional.

De entre las de carácter regional europeo, podemos citar la Recomendación $n^{o} 365$ (1963), Carta Europea del Patrimonio Histórico (1975), las Conclusiones 
de la Conferencia General de Berlín (1982), Carta de Granada (1985), y la última de ellas, la Carta de Cracovia (2000).

Para América del Sur se han elaborado tres documentos, el primero de ellos fue la Carta de Quito, (1967), al que siguieron el Coloquio sobre preservación de centros históricos (1977) y la Carta de Veracruz (1992).

Pero, por encima de todos los documentos citados, merece la pena reseñarse las cartas del restauro de ámbito nacional elaboradas en Italia y que son la base sobre la que se mueven las disposiciones gubernamentales de los principales países de nuestro entorno. El primer documento fue la Carta del restauro (1932) que estuvo vigente hasta 1972, año en que se redactó la siguiente. Y el tercer documento, con miras más amplias, es la Carta del restauro de 1987 de la conservación y restauración de los objetos de arte y cultura, todavía vigente. Y hemos señalado intencionadamente la amplitud de miras de quienes elaboraron el documento ya que, si bien las dos primeras cartas se centraban en las actuaciones sobre las obras arquitectónicas y pictóricas, la de 1987 establece que su campo de actuación se dirige, además, a obras de figuración plana sobre cualquier soporte (mural, de papel, textil, lígneo, de piedra, metálico, cerámico, vítreo, etc.), tal y como se especifica en el artículo 1.

Para una mejor comprensión de cuanto decimos remitimos al lector a la bibliografía que incluimos al final de esta comunicación, especialmente al libro de Ana $\mathrm{M}^{\mathrm{a}}$. Macarrón Miguel, Historia de la conservación y la restauración.

\section{El concepto de restauración a la luz de la Carta del Restauro}

La Carta del Restauro de 1987 establece en su artículo 2 las definiciones de conservación, prevención, salvaguardia, restauración y mantenimiento. En lo concerniente a la restauración, la define así:

Cualquier intervención que, respetando los principios de la conservación y sobre la base de todo tipo de indagaciones cognoscitivas previas, se dirija a restituir al objeto, en los límites de lo posible, una relativa legibilidad y, donde sea necesario, el uso ${ }^{7}$.

Queremos poner especial énfasis en que el documento dice restituir al objeto, y no habla para nada de una reproducción del mismo. Ello nos lleva a la conclusión de que la denominada restauración digital debe entenderse como la intervención en un objeto de esa característica (digital), tendente a cumplir lo determinado en el mencionado artículo para hacerlo legible. Por consiguiente, todo cuanto sea restituir la legibilidad de un objeto sobre un soporte diferente al que se

7 Martínez Justicia, María José. Antología de textos sobre restauración. Universidad de Jaén, 1996. Pág. 196. 
obtuvo no puede ser considerado jamás como una restauración. Ya hemos hecho mención con anterioridad a que nadie llamaría restauración a la restitución de la legibilidad de una obra pictórica, escultórica o arquitectónica, llevada a cabo en soporte digital. ¿Por qué, pues, hemos de aceptar que ello se denomine así en el mundo de la fotografía? ¿Hay algún interés especial oculto que conduce a ello?

Reconocemos no tener respuesta a estas cuestiones. Pero para sentar los principios de una correcta denominación de este proceso utilizado y, tras un periodo de reflexión, hemos encontrado una denominación que propugnamos sea utilizada a partir de ahora, en aras a una correcta diferenciación de los hechos, que exponemos el punto siguiente.

\section{Una nueva denominación}

Las imágenes digitales, elaboradas para mostrar a los espectadores el estado en que supuestamente debieron encontrarse célebres monumentos como el Coliseo, ciudades como Roma o Atenas en el momento de máximo esplendor, esculturas como la Venus de Milo, pinturas e imágenes fotográficas deterioradas, y cuanto pueda pasar por nuestra imaginación que, de acuerdo con la definición inicial pudieran ser consideradas erróneamente como restauración digital, tras indagar en nuestro idioma, deben ser consideradas como recreaciones digitales.

Recreación es, según el $\mathrm{DRAE}^{8}$ en su primera acepción, crear o producir de nuevo una cosa. $\mathrm{O}$, como especifica en el e-diccion@arios Espasa, imitaro reproducir un modelo. Ahí se podrá contemplar la obra tal y como, supuestamente, hubiese sido concebida originalmente sin necesidad de inducir a error al espectador quien, cuando pueda contemplar el original, verá el verdadero estado en que se encuentra.

De esta manera se cumplirá lo determinado en la Carta del Restauro de 1987, en su apartado F:

La intervención de restauración debe salvaguardar la originalidad del documento respetando la forma, la estructura, el soporte o cualquier otro elemento original ${ }^{9}$.

8 Real Academia Española. Diccionario de la lengua española (versión 2.0). Espasa Calpe, Madrid, 1998.

9 Martínez Justicia, María José. Antología de textos sobre restauración. Universidad de Jaén, 1996. Pág. 238 . 


\section{Bibliografía:}

- BOADAS, J.; CASELLAS, L.-E.; SUQUET, M.A. Manual para la gestión de fondos y colecciones fotográficas. CCG, Gerona, 2001.

- BRANDI, Cesare. Teoría de la restauración. Alianza, Madrid, 1989.

- DEL VALLE GASTAMINZA, Félix (Edit.). Manual de documentación fotográfica. Síntesis, Madrid, 1999.

- MACARRÓN Miguel, Ana Mª Historia de la conservación y la restauración. Tecnos, Madrid, 1995.

- MÁRQUEZ, Miguel B. "Restauro y fotografía”, en revista Ámbitos de la Comunicación, $\mathrm{n}^{\circ}$ 2, Sevilla, enero-junio 1999, págs. 127-134. [En línea]. <http://www.ull.es/publicaciones/latina/ambitos/2/marquez.html>. [Consulta: 22.09.2002].

- MARTÍNEZ JUSTICIA, María José. Antología de textos sobre restauración. Universidad de Jaén, 1996.

- MOLINER, María. Diccionario de uso del español (versión 1.1). Gredos, Madrid, 1997.

- Real Academia Española. Diccionario de la lengua española (versión 2.0). Espasa Calpe, Madrid, 1998.

- RIEGO, Bernardo, et al. Manual para el uso de archivos fotográficos. Tres Diseño Gráfico, Santander, 1997.

- VV.AA. La fotografía como fuente de información. Diputación Provincial, Huelva, 1995.

- VILA, Lluís. "Restauració digital d'imatges", en VV.AA. La imatge $i$ la recerca històrica. Ponències y comunicacions. IV Jornades Antoni Varés. Ajuntament de Girona, 1996. 